Reseñas. Cuadernos del Ciesal, Rosario, UNR, $\mathrm{N}^{\mathrm{O}}$ 20, 2021. ISSNe 1853-8827. https://cuadernosdelciesal.unr.edu.ar/index.php/inicio

\title{
BARROS, Carlos (2020). La base material de la nación. El concepto de nación en Marx y Engels. Barcelona: EI Viejo Topo. 220 páginas.
}

El reconocido medievalista y fundador de Historia a Debate Carlos Barros, hace años plantea la necesidad de recuperar, en nuestras producciones históricas e historiográficas, la noción de futuro. Sostiene que las corrientes hegemónicas de la academia han eliminado el término futuro del lenguaje historiográfico.

En este libro Barros da pelea contra esa perspectiva, como hace tiempo lo viene haciendo desde su diversa producción histórica e historiográfica. Para ello revisa el concepto de nación, una temática de enorme centralidad teórica e indudable relevancia política en el pasado reciente y en nuestra actualidad. Lo hace historizando el desarrollo de esa noción y realizando un recorrido centrado en la concepción de Marx y Engels.

El autor nos invita a construir una historia comprometida con el presente y el futuro. En tiempos de futuros cada vez más inciertos y peligrosos, en épocas de presentes catastróficos, la necesidad de una historia que se construya desde horizontes de futuro solidarios e igualitarios, se hace cada vez más imperiosa. Retoma su preocupación por construir una historiografía rica y problematizada, que integre como tema central el estudio de las conflictividades sociales, las revueltas y revoluciones, y el impulso de la Historia Inmediata o Actual. Se trata de estudiar los momentos de radicalidad de la confrontación social, para entender que las sociedades, y las ciencias, avanzan a través de rupturas.

Por todo ello, Barros no se restringe a la revisión bibliográfica y erudita, y tampoco reduce su abordaje a un estudio propio de un marxólogo teórico. Su articulación enlaza la reflexión teórica y el profundo conocimiento de la producción de Marx y Engels con los grandes acontecimientos del pasado reciente y de la actualidad, de cara a la proyección de los futuros posibles (dentro del sistema) y los futuros alternativos (transformando la realidad). Para ello destaca la importancia de comprender "la base material de la nación", con el objetivo de no subestimar su nivel de influencia e importancia en la vida concreta de las clases sociales y tampoco desbarrancar en posturas chauvinistas o excluyentes. Se trata de construir un camino hacia un nuevo orden social, edificado en base a la solidaridad y la cooperación entre los diversos grupos humanos que conformamos este planeta que la humanidad ha puesto en riesgo.

La articulación entre clase(s) y nación(es) atraviesa el libro, destacando que también la nación es, en última instancia, un hecho económico. Esa dimensión es la que el empirismo mecanicista 
que se enseñoreó sobre las perspectivas más difundidas del marxismo en el siglo XX (deriva stalinista mediante) negó, subestimando el peso que la nación tuvo sobre la clase obrera. Analizar cómo ambas categorías se entrelazan continuamente, es imprescindible para hacer verdaderos análisis de fuerzas que puedan direccionarnos en el camino de una necesaria estrategia de poder.

Para ello Barros retoma la perspectiva histórica, siempre sostenida por Marx y Engels. La apuesta a que el desarrollo de la cosa misma constituye la definición real, desechando el apriorismo metodológico que pretende congelar una realidad en continuo movimiento y transformación. Se trata, en definitiva, de recuperar el enfoque dialéctico y el método histórico. Desde esa mirada se destaca la importancia del concepto de nación para comprender los procesos de reproducción social y las dinámicas de acumulación y apropiación del capital.

Estamos, por todo lo destacado, ante un libro clave que resume el enfoque clásico del marxismo acerca del problema de la nación y su interrelación con las clases sociales y el desarrollo del capitalismo. Transitan sus páginas decenas de autores y referencias, de Braudel a Lowy, de Malthus a Bauer, pasando por Vilar, Poulantzas, Lenin, Bloch, Rodolsky, Bakunin, Gramsci y muchos otros. Resalta la importante recuperación del aporte de Borojov (1970), autor casi ignorado por la mayoría de las corrientes que se referencian en el amplio campo del marxismo. El texto revisa una producción originalmente redactada, en sus términos generales, en 1985. Ello quizás explica que la fundamental temática de género recién aparezca en las páginas finales, a modo de uno de los elementos que debe ser incorporado en estudios a futuro, que profundicen en otras derivas de la nación y el nacionalismo.

Así también parece fundamental incorporar a esta reflexión a un conjunto de autorxs que han provocado, con sus intervenciones prácticas y teóricas, inflexiones claves en la reflexión sobre la nación y los nacionalismos. El aporte de Rosa Luxemburgo constituye, sin dudas, una exploración fundamental. Otras contribuciones realizan diversxs revolucionarixs, especialmente quienes han escrito desde países y continentes oprimidos. Sólo por nombrar algunxs de ellxs: José Carlos Mariátegui, Mao Tse Tung, Frantz Fanon, Ho Chi Min, Fidel Castro, Recabarren, Mella, Guiteras, Sandino, José y Farabundo Martí, Ernesto Guevara y tantxs otrxs que injustamente aquí no destaco.

Esa tarea de deseuropeizar el debate sobre la nación (al tiempo que provincializamos a Europa; Chakravarty, 2008) demanda ser incorporada, para construir una herramienta aún más poderosa de cara a la edificación de esa "nación global" a la que Barros nos invita, aquella que nos una y que ya nunca nos divida. Ese futuro alternativo al que convoca Barros, será construido desde los continentes oprimidos por el imperialismo, o no será nunca. 


\section{Gonzalo Pérez Álvarez}

Hacia inicios del siglo XX, Mariátegui (1970) expresaba la necesidad de buscar un camino hacia la necesaria revolución que se construyese desde los países oprimidos: la "creación heroica" de un socialismo indoamericano. El tipo específico de estructura económica y social de nuestros países, su dominación económica y cultural, el colonialismo que aún nos gobernaba (¿o nos gobierna?), hacía necesaria una expresión nueva.

La influencia de Fanon $(1963 ; 1974)$ en los movimientos de liberación nacional que surgen en todo el mundo tras la posguerra de la II Guerra Mundial también es innegable. Su concepto de nación nos dirige al cruce con Benedict Anderson (1993), quién ve a las nacionalidades como una entidad que da sustento a la vida de las personas, que les brinda un sentido y les impide caer en el vacío.

La nación realizaba el anhelo de integrar una comunidad de iguales. Fanon ve esa concepción de la nación como una entidad performativa en la práctica, y desde allí hace un llamado hacia la liberación. Muestra que el capitalismo y el colonialismo, como fenómenos convergentes, deshumanizan a las personas, les arrancan su capacidad creadora.

$\mathrm{Y}$ encuentra en la liberación nacional un camino para quebrar el individualismo, la base del capitalismo. Esa nación era, para lxs colonizadxs, una herramienta para desarrollar la conciencia de su comunidad de intereses. Allí podía comenzar su proceso de des-alienación y convertirse en sujeto colectivo (Fanon, 1963).

Queda también el enorme problema de las naciones sin Estado. Para nuestra Indoamérica eso implica una compleja reflexión sobre las naciones indígenas y sus recorridos históricos. La apertura, en un país como Bolivia, de la noción de un "Estado plurinacional", nos incita a persistir en estas reflexiones, recuperando el pasado histórico de cara a la construcción de un futuro emancipatorio.

Estos señalamientos lejos están de merecer la calificación de críticas y menos aún de desmerecer el gran trabajo de Carlos Barros. Al contrario, es su genealogía sobre el desarrollo del concepto de nación en la obra de Marx y Engels (y en la de Borojov), la que habilita estas y otras lecturas. Es el libro aquí reseñado el que nos convoca a realizarlas desde nuestra praxis situada, en un continente indoamericano en lucha, donde la nación, y sus diversos y complejos significados, sigue siendo parte de esa constante ebullición.

\section{Referencias}

Anderson, B. (1993). Comunidades imaginadas. Buenos Aires: FCE.

Barros, C. (2020). La base material de la nación. El concepto de nación en Marx y Engels. Barcelona: El Viejo Topo. 


\section{Reseñas}

Borojov, D. (1970). Los intereses de clase y la cuestión nacional. En: Nacionalismo y lucha de clases. México: Pasado y Presente, pp. 57-63.

Chakrabarty, D. (2008). Al margen de Europa. ¿Estamos ante el final del predominio cultural europeo?, Barcelona: Tusquets.

Fanon, F. (1974). Piel negra, máscaras blancas. Buenos aires: Schapire Editor.

Fanon, F. (1963). Los condenados de la tierra. México: FCE.

Mariátegui, J. (1970). Obras Completas. Lima: Empresa Editora Amauta.

Gonzalo Pérez Álvarez

Universidad Nacional de la Patagonia

gperezalvarez@gmail.com

ORCID: https://orcid.org/0000-0002-3324-6328 